\title{
QUALIDADES SUBJETIVAS DO TRABALHO DO ARTESÃO: UM ESTUDO SOB A PERSPECTIVA DAS EXPERIÊNCIAS DE ÓCIO
}

\author{
SUBJECTIVE QUALITIES FROM THE ARTISAN WORK: A STUDY UNDER LEISURE EXPERIENCES \\ PERSPECTIVE
}

CUALIDADES SUBJETIVAS DEL TRABAJO ARTESANO: UN ESTUDIO DESDE LA PERSPECTIVA DE LAS EXPERIENCIAS DE OCIO

\author{
Ieda Rhoden* \\ Marlo Renan Rocha Lopes* \\ Adriana Alencar Gomes Pinheiro ${ }^{* * *}$ \\ José Clerton de Oliveira Martins ${ }^{* * * *}$
}

\begin{abstract}
RESUMO
$\mathrm{O}$ artesanato é percebido como a manifestação de um trabalho autogerido e criativo, não desconectado das imposições do mercado capitalista, mas pautado em componentes subjetivos como liberdade percebida, significado intrínseco e desenvolvimento pessoal - alguns dos componentes encontrados nas experiências de ócio tanto em algumas pesquisas empíricas como na literatura especializada. Este artigo objetiva tecer aproximaçôes entre as qualidades subjetivas do trabalho dos artesãos e as qualidades da experiência de ócio. Convoca-se uma abordagem de natureza qualitativa, baseada em uma pesquisa de enfoque etnográfico, alicerçada pela revisão bibliográfica dos conceitos, servindo-se da entrevista em profundidade para coleta dos dados e do Método de Identificação das Qualidades das Experiências de Ócio (MICEO) para análise dos mesmos. Nas articulações contempladas, observa-se que os artesãos enfatizam, dentre outros elementos, a satisfação e o desenvolvimento pessoal presentes no seu ofício. O que os aproxima de uma experiência de ócio.
\end{abstract}

Palavras-chave: Artesanato. Trabalho artesão. Trabalhadores. Experiência de ócio. Desenvolvimento humano.

\footnotetext{
* Doutora em Ócio e Potencial Humano pela Universidade de Deusto, Espanha, título validado no Brasil pela PUC-RS como doutorado em Psicologia Social. Professora da Universidade do Vale do Rio dos Sinos (UNISINOS).

** Graduado em Psicologia pela Universidade de Fortaleza (UNIFOR) e membro do Laboratório OTIUM.

*** Doutora em Psicologia pela Universidade de Fortaleza (UNIFOR) e membro do Laboratório OTIUM. rofessora da Faculdade Paraíso do Ceará.

**** Doutor em Psicologia pela Universidade de Barcelona. Pós-doutor em Estudios de Ocio pela Universidade de Deusto, Espanha. Professor da Universidade de Fortaleza (UNIFOR). Coordenador do Laboratório OTIUM.
} 


\begin{abstract}
Handicraft is perceived as the manifestation of a self-managed and creative work, not disconnected from the impositions of the capitalist market, but guided by subjective components as perceived freedom, intrinsic meaning and personal development - some of the components found in leisure experiences as pointed out by some empirical research and the literature. This article aims to create approaches between the subjective qualities of the work of artisans and the characteristics of leisure experience. This article calls up a qualitative approach, based on an ethnographic research driven by the literature review of the concepts, making use of in-depth interview for data collection and identification method of the qualities of Personal Experiences of Leisure (MICEO) to examination. In the studied articulations it is observed that the artisans emphasize the satisfaction and personal development present in their office, among other things, that approaches those of a leisure experience.
\end{abstract}

Keywords: Artisan work. Handicraft. Workers. Leisure experience. Human development.

\title{
RESUMEN
}

La artesanía es una manifestación de un trabajo autogestionado y creativo, aunque conectado al mercado capitalista. Esta manifestación está pautada por componentes subjetivos tales como libertad percibida, significado intrínseco y desarrollo humano, que son componentes encontrados en la experiencia de ocio, como enseñan algunas investigaciones empíricas y la literatura especializada. Este artículo tiene por objetivo enseñar las semejanzas entre las cualidades subjetivas del trabajo artesano y las cualidades de la experiencia de ocio. Se utilizó un abordaje de naturaleza cualitativa, basada en una investigación etnográfica y una revisión bibliográfica de los conceptos, llevándose a cabo entrevistas en profundidad para la recogida de datos y el Método de Identificación de las Cualidades de las Experiencias Personales de Ocio (MICEO) para análisis de los datos. En las articulaciones observadas, se observa que los artesanos enfatizan la satisfacción y el desarrollo personal presentes en su oficio, entre otros elementos, hecho que los acerca a una experiencia de ocio.

Palabras clave: Artesanía. Trabajo artesano. Trabajadores. Experiencia de ocio. Desarrollo humano.

\section{INTRODUÇÃO}

Ompreende-se que o início da prática do artesanato se confunde com o
início da própria história da humanidade, visto que o ser humano sempre
manifestou sua necessidade de produzir utilitários para o uso cotidiano, 
confeccionando adereços, armas e ferramentas diversas. Essa necessidade de produção manual anuncia uma habilidade criativa primordial canalizada em sua forma produtiva para o trabalho e, nesse sentido, o artesanato se configura como uma das mais significativas expressóes da cultura do homem, que através desse ofício forja e transmite os valores e as crenças da comunidade à qual ele pertence (Santos, 2007).

A história aponta, por intermédio da Antropologia, que os primeiros artesãos apareceram no período Neolítico (6.000 a.C.), ocasião em que o homem aprendeu a dar forma à pedra e à cerâmica, bem como a tecer fibras animais e vegetais para produzir ferramentas simples. Indícios das atividades de artesanato no Brasil foram identificados no sudeste do Piauí como pertencentes a essa época, capitaneados por povos indígenas que dedicavam parte de seu tempo à pintura, para a qual utilizavam pigmentos naturais, e à produção de objetos diversos, como cestas e vasos de cerâmica. Eles produziam também, através do artesanato, suas vestimentas tradicionais, tais como tangas, cocares e outras peças cuja matéria-prima advinha da natureza (Matos, 2011).

Entende-se que o trabalho do artesão é aquele realizado principalmente com o uso de suas mãos, mediante a interação entre a criatividade, a habilidade técnica e o componente intelectual requeridos para a confecção de um produto artesanal. Tal ofício é aprendido e transmitido muitas vezes, mas não obrigatoriamente, por intermédio de mestres artesãos, que encontram na herança da atividade do artesanato uma forma de dar continuidade à tradição cultural de um determinado grupo social (Chiti, 2003; Sennett, 2009).

Atualmente entendido como arte e, ao mesmo tempo, ofício que se insere no âmbito da criação e da potência de difusão da cultura, o artesanato se configura como um trabalho em que o seu realizador se vê perpassado pelo desafio de atender às necessidades do sistema capitalista e, ainda assim, propagar os valores de um trabalho que está baseado no usufruto de um tempo diferente do tempo do capital contemporâneo, ou seja, o tempo da contemplação (Sennett, 2009).

De fato, de acordo com alguns autores (Lima, 2005; Sennett, 2009), o artesão parece atuar como protagonista de um trabalho desacelerado, baseado na capacidade de produzir, criar e divulgar seus produtos, frutos de uma forma particular de ofício. Na perspectiva de um processo de trabalho libertador, autogerido e criativo, o artesão buscará nesse modelo uma forma de reproduzir um tempo próprio de trabalhar, não desligado dos ditames da sociedade baseada no capital, mas inserido em um contexto particular de liberdade percebida, satisfação intrínseca e desenvolvimento pessoal. 
Conforme a literatura especializada, esses e outros atributos psicológicos do trabalho artesanal podem estar em consonância com as qualidades subjetivas encontradas em uma possível experiência de ócio. Segundo Aquino e Martins (2007), Cuenca (2008) e Rhoden (2009), o ócio aponta para uma experiência pessoal satisfatória, motivada pela sensação de liberdade percebida e enriquecedora da natureza humana; é uma experiência que deriva de uma atividade engendrada com os próprios recursos do indivíduo que a experimenta, o que o leva a assumir espontaneamente desafios que ele busca superar e à satisfação em transcender seus próprios limites.

No ofício do artesão se encontra a originalidade do fazer, que se vale de liberdade e autonomia, sem que esse trabalho esteja integralmente atado aos imperativos do mercado capitalista. Indivíduo que pensa e executa sua criação, o artesão está inserido no mercado para dele extrair sua renda, o que não o impede, no entanto, de utilizar o seu ofício para manifestar os valores e costumes próprios de sua comunidade, através de um ofício que lhe traga satisfação pessoal e lhe possibilite o desenvolvimento de suas potencialidades (Porto, 1994). No fazer do artesanato, portanto, pode ser possível encontrar algumas das disposições e qualidades subjetivas percebidas em uma experiência de ócio tal como relatada nos estudos especializados (Pinheiro, Rhoden, \& Martins, 2010).

A partir dessa articulação entre algumas características subjetivas do trabalho do artesão e determinadas propriedades qualitativas da experiência subjetiva de ócio, este artigo discorre sobre as aproximações entre as qualidades subjetivas do trabalho dos artesãos da Associação dos Artesãos Mãe Maria das Dores, da cidade de Juazeiro do Norte-CE, e as características basilares da experiência de ócio, tal como apontada na literatura.

Para que essa articulação seja possível, são delimitadas as características subjetivas presentes no ofício dos artesãos, além de convocada a definição de ócio utilizada nos estudos sobre o tema. Os relatos dos sujeitos, coletados nas entrevistas, foram analisados através do Metodo de Indentificación de las Cualidades de las Experiências Personales de Ocio (MICEO), de Rhoden (2004), utilizado aqui como instrumento de apoio à análise dos conteúdos dos relatos dos artesãos. Com o auxílio do MICEO, foi possível constatar se nos relatos dos artesãos havia atributos próprios das experiências de ócio, no que diz respeito ao ofício em questão (artesanato).

Compreende-se que a referida Associação seja relevante para essa proposta, uma vez que, através dela, podem ser compreendidas a natureza do trabalho dos artesãos da palha do milho na região do Cariri, Nordeste brasileiro, e a possível relação que esse ofício resguarda com as experiências de ócio, tipicamente 
reconhecidas pela literatura como experiências de desenvolvimento pessoal, qualidade de vida e desfrute (Cuenca, 2008). Nessa perspectiva, foi possível investigar como o artesão nordestino que trabalha com a palha do milho experimenta seu trabalho, quais os componentes subjetivos envolvidos em seu ofício e como esses componentes podem ser reconhecidos à luz dos estudos do ócio.

\section{APORTES METODOLÓGICOS}

\subsection{Natureza e abordagem da pesquisa}

Este artigo é de natureza qualitativa, baseado em uma pesquisa de enfoque etnográfico e alicerçado pela revisão bibliográfica dos principais conceitos teóricos envolvidos. Segundo Minayo (2012), a pesquisa qualitativa revela preocupação menor com a generalização, anunciando um interesse maior com o aprofundamento e a abrangência da compreensão dos fenômenos subjetivos. Optou-se pela metodologia qualitativa neste trabalho, pela sua valia em prospectar o elemento subjetivo dos sujeitos da pesquisa, privilegiando a sensibilidade dos discursos coletados e as nuances necessárias à interpretação desses dados (Minayo, 2012).

De acordo com Cervo, Bervian e Silva (2007), a revisão bibliográfica, por sua vez, busca problematizar uma questão central, utilizando-se neste estudo as referências que os pesquisadores consideraram relevantes para o debate em pauta. Para este artigo, foram retomadas as definiçôes teóricas de experiências de ócio, a partir do que se tornou factível realizar as articulaçôes que o trabalho propôs.

Os relatos que compõem os dados analisados neste artigo foram coletados com base em uma abordagem de inspiração etnográfica, entendida aqui como trabalho de campo desenvolvido mediante a observação participante, ao longo de um período de tempo suficiente para se capturarem significados relevantes da cultura investigada (Aguirre, 1995). A utilização da etnografia, neste estudo, caracteriza-se pelo emprego da observação participante, desenvolvida no âmbito da cultura da Associação dos Artesãos Mãe Maria das Dores. Nesse contexto, a abordagem etnográfica possibilitou a inserção, a observação e a participação dos pesquisadores na cultura observada, assim como forneceu a possibilidade $\mathrm{da}$ apreensão dos discursos dos artesãos, apoiada no arcabouço teórico que subsidia esta proposta. 


\subsection{Lócus e participantes da pesquisa}

A pesquisa de campo foi realizada na Associação dos Artesãos Mãe Maria das Dores, na cidade de Juazeiro do Norte-CE. A Associação foi fundada no ano de 1984 pelas freiras da Congregação Irmãs de Nossa Senhora e pelo monsenhor Murilo de Sá Barreto, com o intuito de congregar os artesãos que trabalhavam com a palha do milho, na região do Cariri, organizando a produção e a venda das peças artesanais e conferindo um caráter mais formal ao ofício. Desde então, a Associação reúne os artesãos da palha do milho na cidade de Juazeiro do NorteCE, para onde atrai pessoas de diferentes partes do país interessadas nas peças produzidas pelos artesãos associados.

A Associação é composta por 23 associados, dos quais integraram o universo da pesquisa apenas os que lá trabalham há mais de dez anos, período considerado suficiente para que esses sujeitos tenham vivenciado ou experimentado sentimentos duradouros em relação ao ofício artesanal, facilitando assim sua contribuição na entrevista e estimulando sua capacidade de refletir, reaver e repassar as situaçóes vivenciadas ao longo desse tempo.

Para a aplicação da pesquisa, foram selecionados cinco artesãos da Associação, entre os quais um homem e quatro mulheres, com idades entre 30 e 65 anos. Esses membros integram a Associação há pelo menos uma década, trabalham com a palha do milho como matéria de seus produtos e residem no município de Juazeiro do Norte-CE. Todos os nomes próprios presentes neste artigo são fictícios, tendo em vista garantir o anonimato dos participantes.

\subsection{Técnicas e instrumentos da pesquisa}

Para a coleta dos dados, optou-se pela utilização da entrevista em profundidade, que, de acordo com Aguirre e Martins (2014), permite um aprofundamento das questôes investigadas, coerentemente com o enfoque qualitativo. Nesse tipo de entrevista, ainda de acordo com os autores, tanto o investigador quanto o informante se influenciam (a partir das perguntas feitas e das respostas fornecidas), ainda que caiba ao entrevistador criar o ambiente situacional no qual conteúdos relevantes possam emergir. Levando isso em consideração, as perguntas não podem ter caráter restritivo, uma vez que devem encorajar descrições de sentimentos e valores a partir dos quais se prospectam os componentes subjetivos mais profundos (Aguirre \& Martins, 2014).

Durante as entrevistas, solicitou-se que os artesãos narrassem histórias pessoais sobre as experiências mais memoráveis e significativas vivenciadas no cotidiano do trabalho artesão, dentro da Associação. Para a análise dos conteúdos desses relatos, optou-se pela utilização do Método de Identificação das Qualidades das 
Experiências de Ócio (MICEO), proposto por Rhoden (2004). O MICEO é um instrumento de apoio à análise de conteúdo de relatos e histórias pessoais, elaborado especificamente para identificar os atributos subjetivos constituintes das experiências de ócio, atribuindo importância central às percepções e memória do próprio sujeito acerca de suas emoções, sensações, sentimentos e pensamentos presentes em suas vivências narradas.

De acordo com Rhoden (2004), essa ferramenta de pesquisa se apoia em estudos empíricos e teóricos sobre as experiências de ócio e de lazer como fenômeno psicossocial, realizados predominantemente nos EUA e no Canadá, apresentando-se como um recurso para a identificação de conteúdos subjetivos específicos e contextualizados.

Para esta pesquisa, o MICEO foi escolhido por se tratar de um método baseado na técnica de análise de conteúdo de histórias de vida, ensaios e narrativas pessoais, tornando possível avaliar os fenômenos psicológicos em questão, a partir dos relatos coletados nas entrevistas em profundidade. A preferência pelo MICEO, neste caso, deve-se ao fato de ser um instrumento que permite investigar qualitativamente os relatos das experiências dos artesãos e obter, por seu intermédio, o confronto das principais características subjetivas percebidas pelos sujeitos em seu processo de trabalho artesão com os atributos constitutivos das experiências de ócio, conforme apresenta e descreve o próprio instrumento.

O MICEO apresenta e descreve 13 constructos que servem de parâmetro para a identificação das experiências de ócio, a saber: liberdade percebida; significado intrínseco; desfrute; absorção; apreciação estética; plenitude; intimidade consigo; descanso; ruptura; exigência ou desafio; encontro interpessoal; desenvolvimento humano e autenticidade (Rhoden, 2004). De acordo com a autora, cada sujeito deve apontar, em seu relato, a presença de pelo menos três ou quatro desses atributos numa mesma situação ou vivência, para que se possa afirmar que se trata de uma experiência de ócio (Rhoden, 2009). Desses 13 atributos, sete foram encontrados nos relatos dos sujeitos participantes desta pesquisa, o que será demonstrado a seguir.

\section{APRESENTAÇÃO DOS RESULTADOS E DISCUSSÃO}

No processo de análise dos dados, foram constatados diversos aspectos do trabalho artesanal que os sujeitos da pesquisa relataram como experiências satisfatórias. Esses aspectos foram organizados em categorias que correspondem aos constructos fornecidos pelo MICEO para a apreensão dos componentes da experiência subjetiva do ócio. As relações entre os conteúdos extraídos da pesquisa empírica e os atributos da experiência de ócio serão delineadas a seguir. 
Apreciação estética. Um dos constructos apresentados pelo MICEO como parte integrante da experiência subjetiva de ócio é a apreciação estética, entendida aqui como atenção às qualidades estéticas do ambiente ou da atividade que o indivíduo pratica, a partir do que se estabelece uma possibilidade de contemplação, da prática de um olhar diferenciado, vibrátil, em função do qual é possível experimentar uma satisfação. Nesse processo, o indivíduo percebe a beleza que se apresenta no seu entorno, fruto de seu olhar atento - uma beleza valorizada e conscientemente apreciada (Rhoden, 2004).

O discurso da artesã Clara, que compõe o corpo da Associação há 30 anos, é categórico, quando tomado na perspectiva do trabalho artesanal como encaminhamento de apreciação estética potencializador de uma experiência satisfatória. Segundo Clara, que possui 65 anos de idade e trabalha há 35 anos como artesã:

É possível transformar estas palhas em objetos que às vezes até eu me surpreendo. Parece brincadeira de criança. Depois de anos e anos trabalhando com diversas palhas, vejo que a palha boa mesmo é a palha do milho. Ela parece ouro branco. As tranças que faço parecem deslizar sobre as minhas mãos, transformo em cada coisa linda, que é de se orgulhar! São obras lindas que os romeiros compra e leva para as suas cidades [...] levando junto nossa arte.

A artesã Fernanda apresenta um discurso semelhante. Com 30 anos de idade e uma década e meia trabalhando na prática do artesanato (membro da Associação há 16 anos), ela relata:

Sempre procuro caprichar nas minhas peças, fazer com que elas fiquem as mais bonitas possíveis. Quanto mais me dedico às peças, mais fico com vontade de caprichar para que elas fiquem cada vez mais parecidas com a beleza. Mesmo assim, nenhuma sai igual à outra, todas têm suas características que fazem com que elas fiquem bonitas e todas diferentes [...] sabe? É muito interessante, me orgulho muito disso, principalmente quando nossas peças são elogiadas.

Os artesãos da pesquisa foram unânimes em relatar a satisfação, a admiração pela realização de seu ofício e, neste caso, a consciência da beleza que o trabalho em si engendra. Tal contemplação ocorre não somente com a concretização do produto final que é apresentado aos consumidores, mas durante o processo de confecção, para o qual é necessária a apreciação estética que dará a forma desejada à peça. Como discorre a artesã Francisca, de 63 anos, há 30 anos na Associação, "o intrincado das palhas é sempre motivador e bonito de se ver, porque é belíssimo ver as tranças se transformando nessas obras. É brincadeira, acho que é arte, e o tempo passa voando". 
No tocante aos componentes subjetivos das experiências de ócio estético, Amigo (2009) afirma que esses se caracterizam predominantemente pela riqueza de fenômenos que integram emoção, fruição, aproveitamento e desenvolvimento. São experiências que carregam em si uma dimensão expressiva do ser, vinculando-se ao potencial de desenvolvimento individual. Segundo o autor, essas experiências estéticas residem na contemplação do meio ambiente circundante e da atividade, sobretudo na apreciação da criação artística.

Exigência ou desafio. Outro constructo apresentado pelo MICEO como constituinte das experiências de ócio é o atributo da exigência ou desafio, definidos aqui como elementos que demandam do sujeito um importante empenho físico, emocional ou intelectual, que, nas palavras de Rhoden (2004), "podem tornar a experiência fonte de superação e autoaperfeiçoamento" (p. 5152). Nesse sentido, as atividades que carregam em si exigência e desafio são passíveis de transformar a experiência em algo ainda mais envolvente, o que traz a possibilidade de maior satisfação ao seu término.

A artesã Tamara, de 38 anos, integra o corpo da Associação há 16 anos e resume as exigências de seu ofício da seguinte maneira:

Quando estou fazendo meu artesanato, me sinto desafiada, ainda mais quando tem muitas peças para fazer e vender. Tento fazer tudo no meu tempo [...], mas sou exigente comigo mesma, gosto de fazer rápido e treinar as minhas habilidades. Mal vejo o tempo passar. Mas é comigo mesma esse negócio de sempre fazer mais rápido e querer inovar, fazer trançados diferentes.

O discurso de Tamara retrata de modo categórico os desafios presentes no seu ofício; não apenas no tocante ao que é exigido pelos consumidores (confeccionar mais peças em menor tempo), mas também ao que diz respeito às suas próprias metas (trançar cada vez mais rápido), objetivos que ela persegue para treinar as habilidades e investir em trançados diferentes, dos quais se orgulhe futuramente.

O artesão Cássio, de 36 anos de idade, há 22 anos trabalhando na Associação, relata que "é possível sentir um desafio constante na prática do artesanato, porque tem a exigência do mercado também, além da vontade própria de superar sua produção". A seguir, ele complementa: "Não dá pra dizer que é algo fácil, mas é sempre prazeroso". Aqui, além do desafio imposto pelo próprio artesão de sempre aperfeiçoar-se, há a menção da exigência estabelecida pelo mercado, que transforma o ofício em fonte de renda e, consequentemente, em atividade com fim externo a ela mesma. 
Esses dois discursos representam a condição geral relatada pelos demais artesãos da pesquisa, que expressam o desejo de criar uma obra única que contenha em si o desafio do novo e do experimental, ou seja, do reinventar-se a cada nova criação. Esse reinventar-se é proporcionado pelas metas que os próprios artesãos estabelecem para si, como o lúdico, e pelas demandas do mercado no qual eles estão inseridos e sem as quais o artesanato não constituiria atividade de comércio, aliás. A aceitação consciente de um desafio e a mobilização das habilidades necessárias para superá-lo, extraindo desse processo a satisfação da competência reconhecida, aproximam o trabalho desses artesãos das experiências de ócio abordadas na literatura, tal como apontado por Cuenca (2008).

Liberdade percebida. De acordo com Rhoden (2004), este componente é apreendido a partir da percepção do sujeito de que ele realiza a atividade como um ato de livre escolha, independente e não praticado de maneira alienada, ou seja, realizado de forma consciente, voluntária e lúcida sobre as implicações desse fazer.

Cabe considerar que a liberdade, noção complexa e passível de muitos questionamentos, quando entendida em seu sentido literal, não é abordada aqui como livre-arbítrio pleno e integralmente independente do meio ambiente que condiciona o indivíduo. A liberdade tomada no encaminhamento das experiências de ócio aponta para uma escolha consciente, um estado mental em que a pessoa sente que o que está fazendo é fruto de uma opção e não de uma exigência incontornável. Esse entendimento sobre liberdade percebida advém de Neulinger (1981), autor referência nos estudos da Psicologia do Ócio.

A artesã Clara relata que "[...] o artesanato tem me proporcionado muita satisfação, porque não me sinto na obrigação de fazer o que eu faço, eu faço artesanato por querer, por gostar; tem sido assim por esses longos anos, durante todos os dias... e ainda tenho tempo para fazer as outras coisas que quero.”

A artesã Francisca é consonante: "O artesanato me proporciona prazer, pois tenho liberdade nele, liberdade nos horários. Fio a palha quando quero, no meu canto, do meu jeito. Não gosto de rotina, mas no artesanato eu fico aqui o dia todo, gosto do meu momento com os meus trançados".

Em seu discurso, a artesã Tamara é enfática quando afirma que "a satisfação do artesanato é grande porque não tem patrão me lembrando das obrigações, é tudo no meu tempo, quando posso, quando quero". O discurso do artesão Cássio vai ao encontro dos demais quando ele afirma: "No fazer dos meus trançados, me sinto leve, livre. Porque nunca termino, sempre estou iniciando outra peça, e esse movimento constante é bom. Não tem dia igual ao outro, todos são diferentes". 
Todos os sujeitos entrevistados abordaram, à sua maneira, a condição de se perceberem livres durante o ofício do artesanato. Conforme os relatos aqui discriminados, os artesãos se percebem como não-submissos à obrigação meramente contratual do trabalho, enxergando na prática artesanal a liberdade da escolha pela atividade em si, pelo que ela lhes proporciona, enquanto ação prazerosa. Como se disse anteriormente, não se trata de negar a existência das demandas do mercado capitalista e do tempo particular que ele engendra, mas, antes, de aceitar conscientemente a escolha da atividade praticada pelo seu valor em si e pelas experiências que dela são extraídas.

Nas palavras de Munnè (1996), os estudiosos das experiências de ócio tiveram que "reservar um lugar para as atividades intermediárias nas quais ambos os fenômenos [ócio e trabalho] se combinam, acontecendo, ao mesmo tempo, obrigação e liberdade" (p. 431). Pois, de acordo com o autor, o comportamento entendido como livre não se dá de maneira absoluta, estando sempre atrelado às exigências externas ao sujeito, o que, no entanto, não o impede de se apossar da atividade e tomá-la para si como fonte de desenvolvimento e satisfação.

Significado intrínseco. Mais um constructo central para análise e que constitui outro dos atributos subjetivos das experiências de ócio, de acordo com o MICEO, é o significado intrínseco. De acordo com Rhoden (2004), o significado intrínseco se configura como a expressão da autodeterminação do indivíduo que pratica a atividade, anunciando um desejo pessoal e uma vontade consciente de realizá-la, sem que isso dependa de uma recompensa externa a ela. Por isso, entende-se que se a satisfação advém da realização da atividade por ela mesma, sua motivação reside no significado intrínseco, muito embora possa haver, no processo de realização da mesma atividade, motivações extrínsecas, externas ao indivíduo e provenientes do ambiente (Neulinger, 1981).

A artesã Tamara expressa deste modo a motivação presente no seu trabalho:

No começo, sim, foi difícil, mas agora são outros tempos. Até o sol forte na hora da colheita do milho me dá prazer. Não me cansa tecer a palha e ver ela se transformando em peças lindas. E essas peças são resultado do meu esforço, elas têm um pouco de mim, cada uma. Saber disso me motiva dia a dia.

A artesã Francisca relata, por sua vez, o seguinte: "Não preciso mais trabalhar com o artesanato, falo em me aposentar dele, mas sinto falta. Não consigo ficar um dia sem trançar a palha do milho, a vontade vem de dentro, o querer é grande". A artesã Clara comenta: "Quando estou na Associação fazendo meu trabalho, esqueço o mundo lá fora, me dedico somente ao que eu faço lá. Para 
mim, o trabalho com a palha é suficiente, me basta. Não ganho nada pensando em ter outra ocupação".

A satisfação no fazer artesanal, o desejo de produzir as peças a partir do trançado da palha do milho, em suma, a vontade de seguir executando o ofício pelo prazer direto dele extraído, se encaminham para a proposta de vislumbrar no processo laborativo do artesão um componente subjetivo central das experiências de ócio (Aquino \& Martins, 2007; Rhoden, 2004). Os discursos acima apontados sugerem a motivação basilar intrínseca que move esses artesãos para o seu ofício, o que os torna conscientes do papel que desempenham e do desfrute proporcionado por essa atividade em especial.

Desfrute. Um constructo básico para análise, a partir do que propõe o MICEO, é o desfrute consciente durante a atividade praticada, através da qual o indivíduo experimenta um estado mental caracterizado por afetos positivos e frequentemente traduzido como prazeroso. Nesse sentido, o desfrute advém de um contexto de liberdade da escolha, com a qual se pratica alguma atividade, investindo nela habilidades e competências pessoais para superar os desafios que se apresentam com metas próprias da atividade (Rhoden, 2004). Aqui, o desfrute é resultante desse investimento, como retorno da experiência e percepção de que se é capaz de atingir as metas definidas pela atividade.

A artesã Francisca comenta sobre seu trabalho:

"Para mim é diversão, não me sinto trabalhando, é alegria pura. Sinto que sou capaz, não consigo explicar quando vou terminando uma peça. Trançar a palha do milho me traz uma enorme alegria, uma satisfação tão grande”.

A artesã Fernanda é consonante ao relatar sua experiência durante o trabalho:

"O artesanato tem sido uma grande alegria na minha vida, pois sinto uma enorme diversão fazendo meus baús, minhas peças. Não sei te dizer que alegria é essa, mas tem sido bastante prazeroso vir aqui e tecer essas palhas e ficar com as mãos sujas de tinta”.

A artesã Tamara depõe, por sua vez:

"Cada palha que tranço, sinto que vou dando vida à peça, e acho que vem daí o prazer que tenho ao fazer cada peça com carinho".

O desfrute é uma das sensações mais perceptíveis na fala desses artesãos, que anunciam através dele o seu prazer e a sua satisfação na atividade cotidiana do trançado da palha do milho. Esses sujeitos parecem experimentar, em seu 
ofício, o que Rhoden (2009) define como entrar em contato com a realidade de maneira satisfatória, desfrutando as particularidades da atividade em si, vivendo a experiência do trabalho para dele usufruir numa perspectiva de ócio. As exigências e os desafios impostos pelo ofício artesão, no lugar de serem encarados como obstáculos que impedem o fluxo da atividade, são vistos como objetivos que podem ser superados, graças às habilidades de que esses sujeitos dispõem, o que os leva a escolher deliberadamente essa atividade em detrimento de outras. Da consciência desse processo deriva o desfrute, pois "a satisfação de utilizar e desenvolver habilidades explica parte do desfrute experimentado por algumas pessoas no trabalho" (Rhoden, 2009, p. 74).

Encontro interpessoal. Outro constructo abordado aqui refere-se ao encontro interpessoal como mais um componente passível de ser verificado nas experiências de ócio, tal como apontado pelo MICEO. De acordo com Rhoden (2004), no encontro interpessoal, o indivíduo identifica e valoriza como elemento constitutivo de sua experiência a possibilidade de introduzir-se, experimentar ou aprofundar relações interpessoais, o que possibilita o desenvolvimento humano por meio do exercício das habilidades sociais, das trocas interpessoais e de tantas aprendizagens possíveis decorrentes do encontro com o outro.

O artesão Cássio expõe suas relações de trabalho da seguinte forma: "Tive sorte de ter esses amigos aqui da Associação, pois somos como uma família. Ninguém deixa ninguém desanimar: nosso objetivo é trabalhar junto, com alegria. Principalmente nas vendas, gosto de participar, é um momento de festa nossa". A artesã Francisca relata, por sua vez: "Essa coisa de trançar a palha faz as pessoas sentarem numa roda e jogar conversa fora, melhor do que ficar na TV. No domingo vêm meus filhos pra cá, os vizinhos, e quando percebo estão todos conversando, pegando nas palhas, quem sabe e quem não sabe fazer. É divertido". A artesã Clara é enfática ao afirmar: "Gostamos de trabalhar e estar juntos o tempo todo. Dividimos muitas coisas. Crescemos na palha do milho, e em qualquer dificuldade um sempre incentiva o outro".

A partir desses relatos, a Associação Mãe Maria das Dores surge na condição de comunidade que integra esses artesãos, oferecendo a oportunidade de um ambiente em que são desenvolvidas relações de companheirismo entre os membros associados, o que lhes fornece as bases do desenvolvimento interpessoal que cada um apreende para si. Tal como aponta Cuenca (2008), o encontro interpessoal pleno e satisfatório resguarda estreita relação com o ócio, por se tratar de uma experiência em que se confere um sentido compartilhado às percepçóes da atividade realizada, tornando a experiência mais consciente, fortificando-a. Neste caso, o relato dos artesãos aponta a associação da qual fazem parte como a comunidade em que ocorre a troca dessas experiências, estabelecendo uma rede 
solidária de encontro em torno de uma atividade específica, na qual cada sujeito tem a oportunidade de desenvolver-se enquanto artífice e pessoa.

Desenvolvimento humano. O último constructo abordado aqui, a partir do que é proposto pelo MICEO, diz respeito ao desenvolvimento humano como componente integrante das experiências de ócio. Segundo Rhoden (2004), o desenvolvimento humano expressa o crescimento e a transformação de uma pessoa nos âmbitos cognitivo, afetivo e ou físico. Esse desenvolvimento configurase como uma experiência percebida de mudança, seja pessoal ou grupal, obtida a partir dos impactos e interações dos demais componentes subjetivos da experiência de ócio (Rhoden, 2004), o que pode resultar na melhora da autoestima, na promoção da saúde mental e no incremento da qualidade de vida.

O discurso dos sujeitos entrevistados destaca o desenvolvimento humano no processo de trabalho do artesão sob diferentes aspectos. Nesse ponto, a artesã Fernanda declara: "Na Associação, sinto que venho crescendo a cada ano. Sinto que cresço com o meu trabalho, pois com ele consigo tudo o que quero. Como o artesanato tem me proporcionado tudo até agora, sinto que cresço com ele". O artesão Cássio é consonante com essa visão quando afirma: "Cresci a partir do trabalho artesanal, a palha do milho transformou minha vida. Minhas habilidades manuais ajudaram a transformar outras vidas além da minha. Adquiri, além dos meus móveis, mais maturidade para a vida".

A artesã Tamara, por sua vez, afirma: "Só melhorei com o artesanato durante todos esses anos, sei que sei fazer e procuro melhorar sempre o que já sei. Com o artesanato, melhorei minha qualidade de vida, melhorei minha casa, minha autoestima". A artesã Francisca reitera: "O processo de trabalho com a palha do milho me proporciona desenvolver novas técnicas, o que melhora minha produção e minha qualidade como trabalhadora. Só ganho com esse trabalho, tudo que tenho veio dele $[\ldots]$ ".

Tais relatos se encaminham para o entendimento de que o artesanato possibilita o aprimoramento das habilidades desses sujeitos, que desenvolvem paralelamente sua relação afetiva com o ofício em questão, do qual dizem ter obtido melhorias significativas para as suas vidas. Isso sugere que a natureza e o conteúdo da atividade, se tomados como significativos pelo sujeito que busca se desenvolver, potencializam valores e competências pessoais, pois permitem que esse sujeito marque desafios e avance em sua ação, ao longo do tempo (Monteagudo, Cuenca, Bayón, \& Kleiber, 2013). Para os artesãos entrevistados, esse desenvolvimento humano assume a forma das conquistas, materiais e imateriais, que foram obtidas a partir da prática do artesanato. 
Como enfatizado e tão bem amparado por Aquino e Martins (2007), Cuenca (2008), e Rhoden (2009), dentre outros, o ócio, do ponto de vista individual, tem relação estreita com a vivência de situações prazerosas e satisfatórias, podendo ser compreendido a partir de duas perspectivas: seus componentes objetivos, as atividades e açôes desenvolvidas no ambiente, e subjetivos, os estados mentais emergidos durante a experiência.

Nesse sentido, o ócio é apreendido como uma experiência que emerge de uma situação livremente escolhida e desfrutável, da qual o indivíduo extrai satisfação e desenvolvimento humano. Nas palavras de Francileudo (2009), "a vivência do ócio se relaciona a valores que estão ligados à dimensão interna da pessoa, como o bem-estar, o prazer, a diversão e a felicidade" (p. 211). Esses valores, com os quais o indivíduo entra em contato a partir da experiência da atividade, dignificam a vida e desenvolvem o seu projeto existencial.

\section{CONSIDERAÇÕES FINAIS}

Como visto anteriormente, o ócio é compreendido como uma experiência particular, gratuita, livre e edificante para a vida do ser humano, constituindo uma experiência vivenciada de maneira satisfatória e significativa para o indivíduo. Nessa linha de pensamento, ele é considerado como uma experiência integrada, a partir de determinados componentes subjetivos que, quando percebidos conscientemente, no fazer de uma atividade, concedem um significado à ação e possibilitam o desenvolvimento pessoal, implicando os indivíduos em sua essência afetiva.

Este artigo apresentou sete importantes constructos descritores das experiências de ócio e os articulou com os relatos de cinco artesãos que integram a Associação Mãe Maria das Dores, em Juazeiro do Norte-CE, na tentativa de aproximar o ofício cotidiano desses trabalhadores com as proposições teóricas que definem as experiências de ócio.

A partir das articulaçôes contempladas nesse estudo, observou-se que os artesãos enfatizaram de maneira notável sua relação afetiva agradável e satisfatória com o artesanato, valorizando sua liberdade diante do trabalho artesão e a percepção de desenvolvimento pessoal associada ao ofício em questão. Para esse artesão, importa não apenas a forma como a sua obra se apresenta para o público depois de concebida, mas, também, o processo subjetivo e enriquecedor que ele experimenta, durante a confecção de sua obra. Nesse processo, considera-se evidente a emergência dos componentes subjetivos, considerados parte integrante das experiências de ócio, o que se encaminha para o entendimento de que, no trabalho desses artesãos, foi possível apreender condiçōes que se aproximam do ócio, tal como definido na literatura. 


\section{REFERÊNCIAS}

Aguirre, A. (1995). Etnografia: metodologia cualitativa en la investigación sociocultural. Marcombo: Barcelona.

Aguirre, A., \& Martins, J. C. (2014). A pesquisa qualitativa de enfoque etnográfico. Coimbra: Grácio Editor.

Amigo, M. L. (2009). Beneficios de la experiencia de Ocio Estético. Mal-estar e Subjetividade, 9(2), 397-432.

Aquino, C. A., \& Martins, J. C. (2007). Ócio, lazer e tempo livre na sociedade do consumo e do trabalho. Mal-estar e Subjetividade, 7(2), 479-500.

Cervo, A., Bervian, P., \& Silva, R. da (2007). Metodologia científica. São Paulo: Pearson Prentice Hall.

Chiti, J. F. (2003). Artesania, Folklore y arte popular. Buenos Aires: Ediciones Condorhuasi.

Cuenca, M. (2008). Ócio humanista. In M. Cuenca, \& J. C. Martins. (Orgs.), Ócio para viver no século XXI. Fortaleza: As Musas, p. 33-55.

Francileudo, F. A. (2009). Desvelando o valor do tempo para si: um estudo hermenêutico sobre o sentido ontológico do ócio. (Dissertação de mestrado). Universidade de Fortaleza, Programa de Pós-graduação em Psicologia,

Lima, R. (2005). Artesanato: cinco pontos para discussão. Recuperado a partir de http://www.iphan.gov.br

Matos, E. H. S.F. (2011, Fevereiro). Dossiê técnico: racionalização do processo produtivo do artesanato. Brasília: Serviço Brasileiro de Respostas Técnicas. CDT/UNB. Recuperado a partir de http://respostatecnica.org.br/dossietecnico/downloadsDT/NTY4Mg==

Minayo, M. C. (2012). Análise qualitativa: teoria, passos e fidedignidade. Ciência e Saúde Coletiva, 17(3), 621-629.

Monteagudo, M. J., Cuenca, J., Bayón, F., \& Kleiber, D. (2013). Ócio ao longo da vida: as potencialidades dos itinerários de ócio para a promoção do desenvolvimento humano. Revista Lusófona de Estudos Culturais, 2, 156-173.

Munné, F. (1996). Psicología social del ocio y del tiempo libre. In J. L. Alvaro, A. Garrido, \& J. R. Torregrosa. (Orgs.), Psicología social aplicada. Madrid: McGraw-Hill, p. 429-448. 
Neulinger, J. (1981). The psichology of leisure. Springfield: Charles C. Thomas.

Pinheiro, K. F., Rhoden, I., \& Martins, J. C. (2010). A experiência de ócio na sociedade hipermoderna. Mal-estar e Subjetividade, 10(4), 1131-1146.

Porto, A. S. (1994). Mãos de mestre: itinerários de arte e tradição. São Paulo: Maltese.

Rhoden, I. (2004). Experiências personales de ócio: desarrollo de una herramienta para identificación de sus cualidades subjetivas. (Tese de Doutorado). Universidad de Deusto, Bilbao, Instituto de Estudios de Ocio.

Rhoden, I. (2009). O ócio como experiência subjetiva: contribuições da psicologia do ócio. Mal-estar e Subjetividade, 9(4), 1233-1250.

Santos, E. T. (2007). Exportaçôes de artesanato do Ceará no período de 2004 a 2006: desafios e oportunidades. (Dissertação de Mestrado). Programa de Pósgraduação em Administração, Universidade de Fortaleza, Fortaleza.

Sennett, R. (2009). O artifice. Rio de Janeiro: Record. 